\title{
The Cytotoxic Properties of Baeckea frutescens Branches Extracts in Eliminating Breast Cancer Cells
}

\author{
S. H. Shahruzaman, ${ }^{1}$ M. F. Mustafa, ${ }^{1}$ S. Ramli, $^{2}$ S. Maniam $\left(\mathbb{D},{ }^{3}\right.$ \\ S. Fakurazi $\mathbb{D}^{1},{ }^{1}$ and S. Maniam $\mathbb{( i )}^{1}$ \\ ${ }^{1}$ Department of Human Anatomy, Faculty of Medicine and Health Sciences, Universiti Putra Malaysia, 43400 UPM Serdang, \\ Selangor Darul Ehsan, Malaysia \\ ${ }^{2}$ Faculty of Pharmacy, UiTM Cawangan Selangor, 42300 Puncak Alam, Selangor Darul Ehsan, Malaysia \\ ${ }^{3}$ Monash University, Wellington Road, Victoria 3800, Australia
}

Correspondence should be addressed to S. Maniam; sandra@upm.edu.my

Received 15 February 2019; Accepted 26 March 2019; Published 23 April 2019

Academic Editor: Stefania Marzocco

Copyright (c) 2019 S. H. Shahruzaman et al. This is an open access article distributed under the Creative Commons Attribution License, which permits unrestricted use, distribution, and reproduction in any medium, provided the original work is properly cited.

\begin{abstract}
Breast cancer is the leading cause of cancer death in women in over 100 countries worldwide and accounts for almost 1 in 4 cancer cases among women. Baeckea frutescens of the family Myrtaceae has been used in traditional medicine and is known to possess antibacterial, antipyretic, and cytoprotective properties. In this study, we investigated the role of Baeckea frutescens branches extracts against human breast cancer cells. Baeckea frutescens branches extracts were prepared using Soxhlet apparatus with solvents of different polarity. The selective cytotoxic activity and the glucose consumption rate of Baeckea frutescens branches extracts of various concentrations (20 to $160 \mathrm{ug} / \mathrm{ml}$ ) at 24-, 48-, and 72-hour time points were studied using MTT and glucose uptake assay. The $\mathrm{IC}_{50}$ values in human breast cancer (MCF-7 and MDA-MB-231) and mammary breast (MCF10A) cell lines were determined. Apoptotic study using AO/PI double staining was performed using fluorescent microscopy. The glucose uptake was measured using 2-NBDG, a fluorescent glucose analogue. The phytochemical screening of major secondary metabolites in plants was performed. This study reports that Baeckea frutescens branches extracts showed potent selective cytotoxic activity against MCF7 cells compared to MDA-MB-231 cells after 72 hours of treatment. Evidence of early apoptosis which includes membrane blebbing and chromatin condensation was observed after 72 hours of treatment with Baeckea frutescens branches extracts. Interestingly, for the glucose uptake assay, the inhibition was observed as early as 24 hours upon treatment. All Baeckea frutescens extracts showed the presence of major secondary metabolites such as tannin, triterpenoid, flavonoid, and phenol. However, alkaloid level was unable to be determined. The identification of Baeckea frutescens and its possible role in selectively inhibiting glucose consumption in breast cancer cells defines a new role of natural product that can be utilised as an effective agent that regulates metabolic reprogramming in breast cancer.
\end{abstract}

\section{Introduction}

Baeckea frutescens of the family Myrtaceae and subfamily Myrtoideae or locally referred to as Cucur Atap is a small tree which is found in Peninsular Malaysia and Sumatra [1] and distributed along the coastal areas of Southern China and Australia[2]. Traditional medicinal properties of $B$. frutescens were reported in treating influenza, dyspepsia, jaundice, dysentery, measles, and irregular menstrual cycles [3]. The bioactive constituents were shown to possess various properties such as antibacterial [4-6], antioxidant [7], and anti-inflammatory [8] ones as well as preventing arteriosclerosis by inhibiting LDL oxidation [9]. The cytotoxic effects of the methanolic derivatives were shown against leukaemic cells [10] and human lung, pancreatic, and breast cancer cells [6]. The hexane fraction of $B$. frutescens has been less extensively studied. Although little is known about the properties of the hexane fraction, it has recently been reported to possess moderate cytotoxic effect against human lung carcinoma [7].

To our knowledge, several metabolites were extracted from $B$. frutescens and structures of these metabolites were elucidated [1-28]. To date, there is yet no scientific research 
to elucidate the mechanism of $B$. frutescens in cancer cells. The aim of the study is to investigate the cytotoxic effect of $B$. frutescens branches extracts against breast cancer cells.

\section{Materials and Methods}

2.1. Extracts Preparation. B. frutescens or Cucur Atap was collected from Forest Research Institute Malaysia (FRIM) Research Station in Setiu, Terengganu, and its voucher specimen (Voucher number: KLU 47909) was deposited at Institute of Bioscience, Universiti Putra Malaysia. The branches of $B$. frutescens were cleaned and air-dried under shade for 7 consecutive days. The dried branches of $B$. frutescens were pulverized into coarse powder separately [7]. The powder was grounded and filtered using $0.9 \mathrm{~mm}$ filter membrane by vacuum pump to remove the debris and fibres. The coarse powder was extracted for $50 \%$ ethanol (B50), 70\% ethanol (B70), 90\% ethanol (B90), and water (WB) for 8 days, and finally the extractions were dried under a vacuum rotary evaporator (CCA-1110, Eyela, Tokyo, Japan).

2.2. Cell Lines. Human MCF-7 breast carcinoma cells (ATCC, USA) were grown as a monolayer in DMEM supplemented with $100 \mathrm{ug} / \mathrm{ml}$ streptomycin, $100 \mathrm{ug} / \mathrm{ml}$ penicillin, and $10 \%$ FBS. Human mammary breast cell lines, MCF10A cells (ATCC, USA), were cultured in DMEM/Ham's F-12 supplemented with $20 \mathrm{ng} / \mathrm{ml}$ epidermal growth factor (EGF), $0.01 \mathrm{mg} / \mathrm{ml}$ insulin, $500 \mathrm{ng} / \mathrm{ml}$ hydrocortisone, and $5 \%$ horse serum. Both cells were maintained at $37^{\circ} \mathrm{C}$ in $5 \% \mathrm{CO}_{2}$.

2.3. Determination of Cytotoxicity. The cytotoxicity of MCF7 cells treated with $B$. frutescens extracts was determined by measuring the $\mathrm{IC}_{50}$ using the colorimetric MTT assay as previously described by Mosmann [29]. Briefly, cells were plated into 96-well microplates at a density of $5 \times$ $10^{3}$ cells/well. Cells were cultured at $37{ }^{\circ} \mathrm{C}$ and treated at various time points $(24-72 \mathrm{~h})$ with various concentrations of extracts $(0-1000 \mu \mathrm{g} / \mathrm{ml})$, and etoposide was used as a standard drug whilst DMSO was used as the vehicle control (control). The formazan grains were dissolved in DMSO, and the absorbance at $570 \mathrm{~nm}$ (Wavelength range: 550-600 nm) was read using an ELISA plate reader with the reference wavelength higher than $650 \mathrm{~nm}$.

2.4. Glucose Consumption Assay. 2-NBDG was used to measure glucose uptake as previously described by Hassanein et al. [30] Briefly, MCF-7 cells were seeded (0-30,000 cells/well) in clear-bottomed 96-well microplates in triplicates. Cells were allowed to adhere overnight at $37^{\circ} \mathrm{C}$ before performing uptake assay. After overnight incubation, the cells were treated at three different concentrations; lower than $\mathrm{IC}_{50}$ value (low), $\mathrm{IC}_{50}$ value (IC50), and higher than $\mathrm{IC}_{50}$ value (high) extracts for 24, 48, and $72 \mathrm{~h}$ and DMSO was used as the vehicle control (control). The wells were washed twice with phosphate-buffered saline (PBS) and incubated with 2-NBDG $(100 \mu \mathrm{M})$ for $10 \mathrm{~min}$ at $37{ }^{\circ} \mathrm{C}$ in a humidified atmosphere of $5 \% \mathrm{CO}_{2}$. The reaction was stopped by adding twofold volume of ice-cold PBS and the wells were rinsed with ice-cold PBS for three times. The fluorescent signals before (autofluorescence) and after adding $100 \mu \mathrm{M} 2-\mathrm{NBDG}$ were measured (using the $485 \mathrm{~nm}_{\text {ex }}$ and $520 \mathrm{~nm}_{\text {emiss }}$ filter set). 2-NBDG uptake was also inhibited pharmacologically using WZB117 $(10 \mu \mathrm{M})$, a glucose transporter inhibitor (Sigma).

2.5. Acridine Orange and Propidium Iodide Staining. Cell death in MCF-7 cells was detected using propidium iodide (PI) (Sigma Aldrich, USA) and acridine-orange (AO) (Sigma Aldrich, USA) double staining and examined under fluorescence microscope. Briefly, treatment was performed in a 6well plate. MCF-7 cells were plated at a concentration of $1 \times 10^{6}$ cells $/ \mathrm{ml}$. The $\mathrm{IC}_{50}$ of the three extracts were used to treat the cells and DMSO was used as the vehicle control (control). Cells were then incubated in $37^{\circ} \mathrm{C}$ in $5 \% \mathrm{CO}_{2}$ for 24,48 , and $72 \mathrm{~h}$. The cells were trypsinized and collected into centrifuge tubes and centrifuged at $1,000 \times g$ for $10 \mathrm{~min}$. Supernatant was discarded and the cells were washed twice using PBS following centrifugation at $1,000 \times g$ for $10 \mathrm{~min}$ to remove the remaining media. In total, $10 \mu \mathrm{l}$ fluorescent dyes, AO (10 $\mu \mathrm{g} / \mathrm{ml})$ and PI $(10 \mu \mathrm{g} / \mathrm{ml})$, were added into the cellular pellet at equal volumes. Freshly stained cell suspension was dropped onto a glass slide and covered with coverslip. Slides were observed under ultraviolet- (UV-) fluorescence microscope (Olympus, Japan) within 30 min prior to the fading of the fluorescence colour.

2.6. Phytochemical Screening. $10 \mu \mathrm{L}$ of B. frutescens branches extracts $(1 \mathrm{mg} / \mathrm{mL}$ ethanol) was tested for the presence of tannins, alkaloids, triterpenoids, flavonoids, phenols, and alkaloids. The qualitative results were graded as very high $(++++)$, high $(+++)$, moderate $(++)$, low $(+)$, or not detected (-) based on the intensity of the coloured reaction observed compared with the positive control for the respective chemical reactions. The quantitative results for total content were further determined according to method done by Hisam et al. with slight modification [31]. The absorbance which corresponds to each test (Wavelength range: $435-635 \mathrm{~nm}$ ) was measured by using an ELISA plate reader (Tecan 200, Switzerland).

2.6.1. Total Tannins Content. Five drops of $5 \%$ ferric chloride (Sigma Aldrich) were added to the extract. Formation of blue colour indicates the presence of tannins. $0.01 \mathrm{~g} / \mathrm{ml}$ tannic acid (Sigma Aldrich) was used as the positive control. Absorbance was measured at $560 \mathrm{~nm}$.

2.6.2. Total Triterpenoids Content. The extract was mixed with chloroform and concentrated sulfuric acid was added to the solution. Formation of reddish brown colour at the interface indicates the presence of triterpenoids. $0.01 \mathrm{~g} / \mathrm{ml}$ cholesterol (Sigma Aldrich) was used as the positive control. Absorbance was measured at $635 \mathrm{~nm}$.

2.6.3. Total Flavonoids Content. Drops of $10 \%$ lead acetate were added until formation of yellow precipitate. $0.01 \mathrm{mg} / \mathrm{ml}$ quercetin (Sigma Aldrich) was used as the positive control. Absorbance was measured at $590 \mathrm{~nm}$. 
2.6.4. Total Phenols Content. The extract was mixed with $10 \%$ ferric chloride (Sigma Aldrich) solution and formation of bluish black color indicated the presence of phenols. $0.01 \mathrm{~g} / \mathrm{ml}$ quercetin was used as the positive control. Absorbance was measured at $490 \mathrm{~nm}$.

2.6.5. Total Alkaloids Content. Drops of Dragendorff's reagent (Sigma Aldrich) were added to the extract. Formation of orange/orange reddish brown precipitate showed a positive result. $0.01 \mathrm{~g} / \mathrm{ml}$ quinine sulfate (Sigma Aldrich) was used as the positive control. Absorbance was measured at $435 \mathrm{~nm}$.

2.7. Statistical Analysis. Data were expressed as mean \pm SEM (Standard Error of the Mean). A one-way analysis of variance (ANOVA), followed by Bonferroni post hoc test was employed for statistical analysis. SPSS (version 20) statistical software was used for the analysis of data and $\mathrm{p}<0.01$ was taken as the level of significance.

\section{Results and Discussion}

Two human breast carcinoma cell lines, MCF-7, which are oestrogen receptor positive (ER+) cells, and MDA-MB-231, which are oestrogen receptor negative (ER) cells, were used to determine the cytotoxicity of the $B$. frutescens branches extracts. Etoposide was used as the positive control. In this study, four extracts were prepared using ethanol (B50, B70, and $\mathrm{B} 90$ ) and water (WB) from the branches of B. frutescens using Soxhlet extraction method.

The viability of the human breast-derived cells after treatment with the $B$. frutescens branches extracts at 24, 48, and $72 \mathrm{~h}$ was estimated using MTT assay. No $\mathrm{IC}_{50}$ values were obtained from both cell lines at $24 \mathrm{~h}$ and $48 \mathrm{~h}$ of treatment. The cytotoxic effects of $B$. frutescens branches extracts were only seen at $72 \mathrm{~h}$ against MCF-7 cells. Among the four branches extracts tested, the water extract (WB) did not show cytotoxic activity against MCF-7 at any time point (Figure 1(a)). Amongst the ethanolic extracts, the most potent extract against MCF-7 cells was B70 with $\mathrm{IC}_{50}$ of $53 \mu \mathrm{g} / \mathrm{ml}$ (Figure 1(b)). Data in this study indicates that the oestrogen receptor positive, MCF-7 breast cancer cells responded more favourably to B.frutescens than the triple negative MDA-MB231 cells. Hence, MCF-7 cells were used for further cell death investigation (Figure 1(b)).

MCF10A, a normal human mammary epithelial cell line, was used as normal breast cell model and served as control. The in vitro cytotoxicity of $B$. frutescens extracts was evaluated against MCF10A at three various concentrations: a concentration lower than $\mathrm{IC}_{50}$, the $\mathrm{IC}_{50}$ value, and a concentration higher than $\mathrm{IC}_{50}$. All $B$. frutescens extracts tested showed insignificant cytotoxic activity against the normal human breast cancer cells (Figure 1(c)). This indicates the selective cytotoxic activity of $B$. frutescens towards cancer cells and not normal cells.

B. frutescens is traditionally known to have cytotoxic, anticariogenic, and antibacterial properties $[4,6,10,20]$. Previous study found that baeckenones $F$, which was obtained from $B$. frutescens leaves, showed moderate cytotoxicity against MDA-MB-231 breast cancer cells [13, 22]. The cytotoxic activities of $B$. frutescens leaves were also reported in human leukemic cells $[1,10,20]$ and human pancreatic ones $[13,22]$. Many studies on $B$. frutescens were carried using the leaves and roots [8]. To date, this study is the first to examine the in vitro cytotoxic activity in the MCF-7 breast cancer cells treated with the $B$. frutescens branches extracts.

AOPI staining was used to determine the mode of cell death induced in B. frutescens-treated MCF-7 cells. AO is a nucleic acid selective fluorescent cationic dye that develops a protonated positive charge when it crosses the plasma membrane of viable and early apoptotic cells and intercalates into DNA and RNA to produce green fluorescence [32, 33]. Viable cells were stained green with intact nucleus structure (Figure 2(a)). Dead cells were stained red by PI, which penetrated the nuclear matter where the integrity of the cell membrane was compromised. All three ethanolic $B$. frutescens branches extracts did not show any morphological changes after 24 and $48 \mathrm{~h}$ treatment compared to control. Upon $72 \mathrm{~h}$ treatment, cells treated with $\mathrm{IC}_{50}$ value of $B$. frutescens branches extract exhibited membrane blebbing, chromatin condensation which indicates characteristics of early apoptosis (Figure 2(b)). Interestingly, the morphological changes observed corroborated with the data obtained from the MTT assay at which the $\mathrm{IC}_{50}$ was determined.

Most cancer cells exhibit an exceptionally high glycolysis rate and convert most incoming glucose to lactate in the presence of oxygen and this feature is known as Warburg effect. Warburg effect confers growth advantage to cancer cells when glucose supply is sufficient and this feature could be reflected as a fatal weakness of cancer cells when glucose supply is a problem [34]. Maximizing cancer cell glycolysis rate would possibly exhaust intratumoral glucose, leading cancer cell to death. It has been hypothesized that targeting glucose metabolism may provide a selective mechanism by which cancer cells are eliminated.

Glucose uptake was determined in MCF-7 cells treated with three B. frutescens branches extracts (B90, B70, and $\mathrm{B} 50$ ) at three different concentrations (lower than $\mathrm{IC}_{50}$ value, $\mathrm{IC}_{50}$ value, and higher than $\mathrm{IC}_{50}$ value) for 24,48 , and 72 h. WZB 117, a glucose transporter inhibitor that blocks the uptake of 2-NBDG via glucose transporter 1 (GLUT1), was used as positive control. After $24 \mathrm{~h}$ treatment, all branches extracts at their respective $\mathrm{IC}_{50}$ values significantly inhibited glucose uptake compared to WZB 117 and control. At 48 $\mathrm{h}$ of treatment, all three doses of B90 showed significant inhibition of glucose uptake compared to WZB 117 and control. After 72 h, B90 and B70 showed significant inhibition of glucose uptake compared to WZB 117. In summary, all $B$. frutescens branches extracts at all time points significantly inhibited glucose uptake compared to control (Figure 3). The extracts were also tested against MCF10A, human mammary breast cells. The results clearly showed that there were no significant glucose inhibitions in normal cells by all the extracts tested (Figure 3). This demonstrates that B. frutescens extracts selectively inhibit glucose uptake in MCF-7 cells.

The AO/PI staining and MTT assay showed that the $\mathrm{IC}_{50}$ concentrations of $B$. frutescens branches extracts induced cell death only after $72 \mathrm{~h}$ treatment. However, this did not 


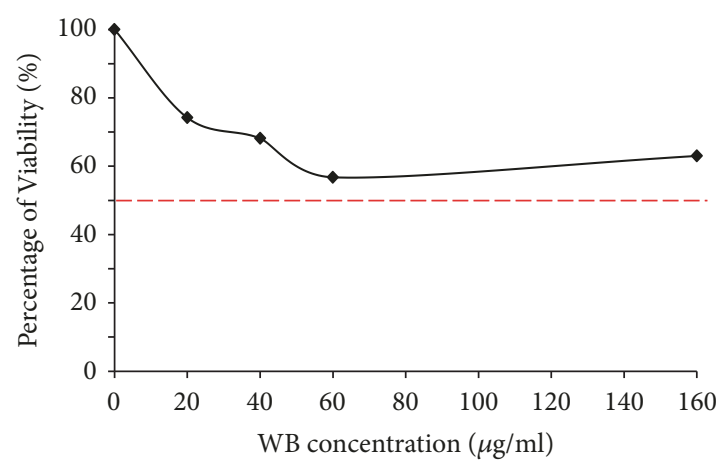

(i)

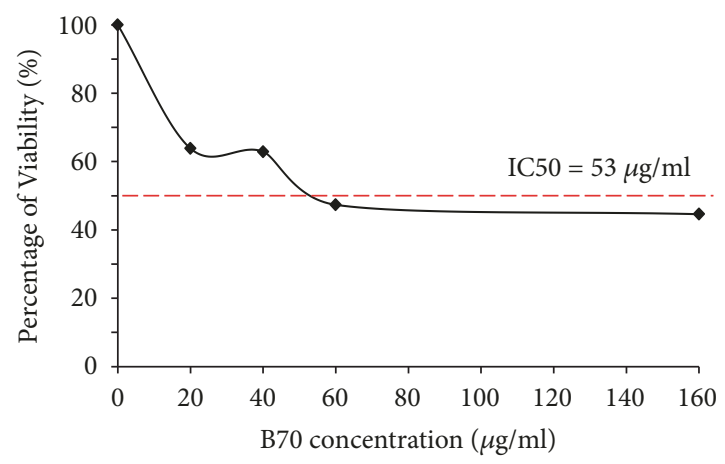

(iii)

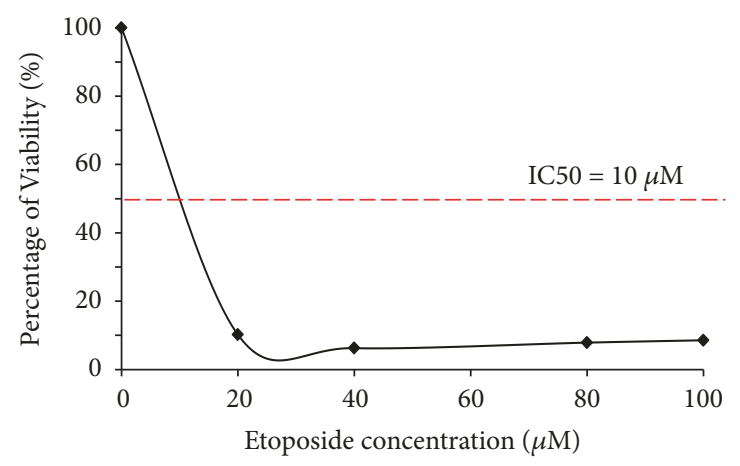

(v)

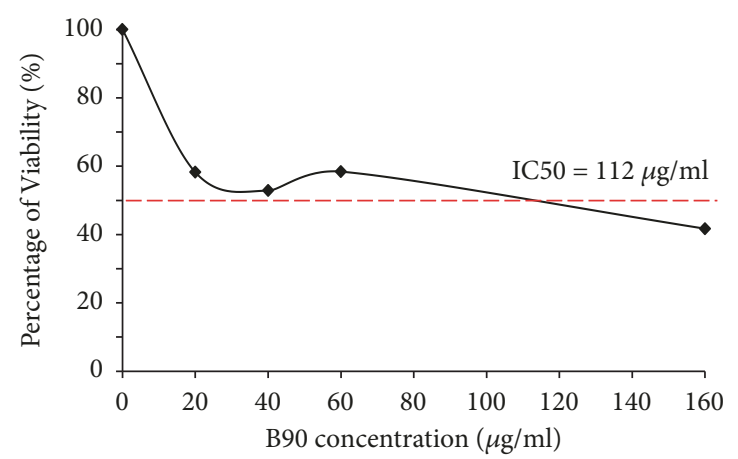

(ii)

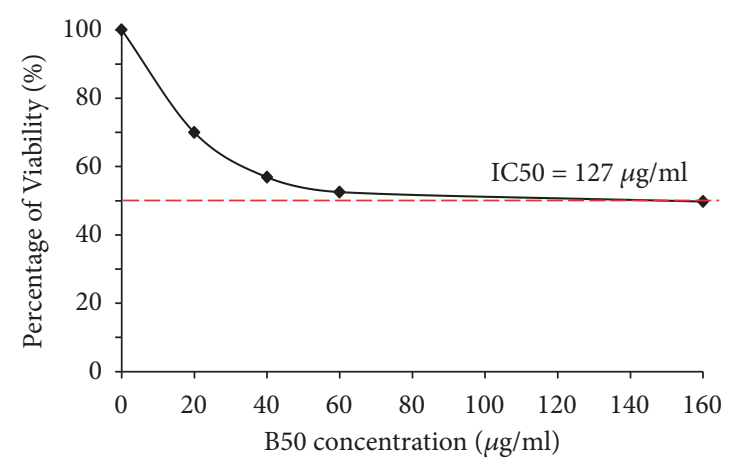

(iv)

(a)

\begin{tabular}{|c|c|c|c|c|c|c|}
\hline & \multicolumn{2}{|c|}{$24 \mathrm{~h}$} & \multicolumn{2}{|c|}{$48 \mathrm{~h}$} & \multicolumn{2}{|c|}{$72 \mathrm{~h}$} \\
\hline & MCF-7 & MDA-231 & MCF-7 & MDA-231 & MCF-7 & MDA-231 \\
\hline WB & ND & ND & ND & ND & ND & ND \\
\hline B90 & ND & ND & ND & ND & $112 \pm 0.53$ & ND \\
\hline B70 & ND & ND & ND & ND & $53 \pm 0.62$ & ND \\
\hline B50 & ND & ND & ND & ND & $127 \pm 0.61$ & ND \\
\hline Etoposide & ND & ND & $8 \pm 0.03$ & ND & $10 \pm 0.02$ & $20 \pm 0.23$ \\
\hline
\end{tabular}

(b)

FIGURE 1: Continued. 


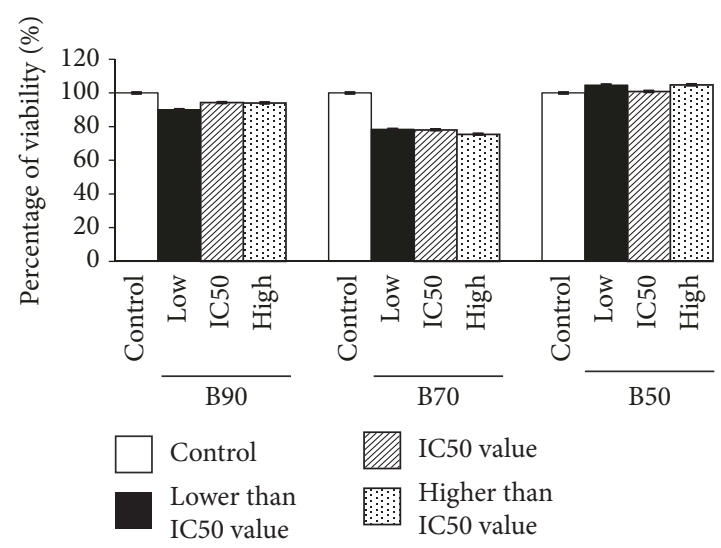

(c)

FIGURE 1: Effects of B. frutescens branches extracts on MCF-7 cell viability. (a) Cytotoxicity was determined using cell viability assay and the $\mathrm{IC}_{50}$ value was calculated as half maximal percentage of cell viability inhibition and it is indicated by the red horizontal line. MCF-7 cells were treated with either (i) WB, (ii) B90, (iii) B70, or (iv) B50 or (v) etoposide, which served as positive control for $72 \mathrm{~h}$. Data is expressed as mean \pm standard error mean based on six independent experiments with triplicate wells for each concentration. (b) $\mathrm{IC}_{50}$ values of B90, B70, B50, and WB against MCF-7 and MDA-MB 231 cells after 24, 48, and $72 \mathrm{~h}$ of incubation. (c) Normal mammary epithelial cells (MCF-10A) were treated with either B90, B70, or B50 at three different concentrations: lower than $\mathrm{IC}_{50}$ value (low), $\mathrm{IC}_{50}$ value (IC50), and higher than $\mathrm{IC}_{50}$ value (high) for $72 \mathrm{~h}$. Data is expressed as mean \pm standard error mean based on three independent experiments with triplicate wells for each concentration.

TABLE 1: Qualitative analysis of B. frutescens leaves phytochemical constituents.

(a) Phytochemical constituent of $B$. frutescens branches in $1 \mu \mathrm{g}$

\begin{tabular}{lcccrr}
\hline Extracts & Tannin & Triterpenoids & Flavonoid & Alkaloids & Phenols \\
\hline B90 & $168.41 \pm 0.05$ & $162.30 \pm 0.17$ & $481.17 \pm 0.16$ & ND & $127.96 \pm 0.02$ \\
B70 & $150.52 \pm 0.04$ & $46.37 \pm 0.04$ & $367.00 \pm 0.02$ & ND & $129.99 \pm 0.02$ \\
B50 & $206.19 \pm 0.02$ & $152.30 \pm 0.19$ & $254.50 \pm 0.12$ & ND & $98.32 \pm 0.02$ \\
WB & $90.41 \pm 0.03$ & $13.41 \pm 0.06$ & $104.50 \pm 0.03$ & $44.15 \pm 0.02$ \\
\hline
\end{tabular}

(b) Phytochemical ratio of $B$. frutescens branches in $1 \mu \mathrm{g}$

\begin{tabular}{lcccc}
\hline Compound & Tannin & Triterpenoids & Flavonoid & Phenols \\
\hline B90 & 1 & 1 & 4 & 1 \\
B70 & 3 & 1 & 3 & 3 \\
B50 & 2 & 2 & 3 & 1 \\
WB & 7 & 1 & 8 & 3 \\
\hline
\end{tabular}

correlate with glucose uptake inhibition which was observed as early as $24 \mathrm{~h}$ treatment. These results suggest that modulating glucose uptake is not the main mechanism of $B$. frutescens in inducing cell death. In the current study, B. frutescens extracts were found to inhibit glucose uptake in MCF-7 cells which lack in caspase 3 . It is postulated that decreased glucose uptake observed in $B$. frutescens-treated cells might affect the mitochondria which is involved in inducing cell death. Mitochondria related caspase independent cell death can be triggered by various stimuli such as changes in the amount of ATP generated in the mitochondria and disruption of mitochondrial morphology which results in the release of intermembrane space proteins. The mechanism of $B$. frutescens extracts in modulating glucose metabolism warrants further investigation.
The preliminary phytochemical screening of $B$. frutescens was performed for tannin, triterpenoid, flavonoid, alkaloid, and phenol. The colour intensity or precipitate was used as analytical response for these tests. Presence of tannin, triterpenoid, flavonoid, alkaloid, and phenol were found in all extracts. All four B. frutescens branches extracts showed the presence of tannins, triterpenoids, flavonoid, and phenol except alkaloids (Table 1(a)). The highest tannin and phenol content was measured in B50 and B90, respectively. WB extract has the lowest tannin and phenol content among all four B. frutescens branches extracts. The triterpenoid and flavonoid content were the highest in B90 whilst these secondary metabolites were the lowest in WB extract (Table 1(a)). Ratio of quantitative estimation of tannin, triterpenoid, flavonoid, and phenol in B. frutescens is 


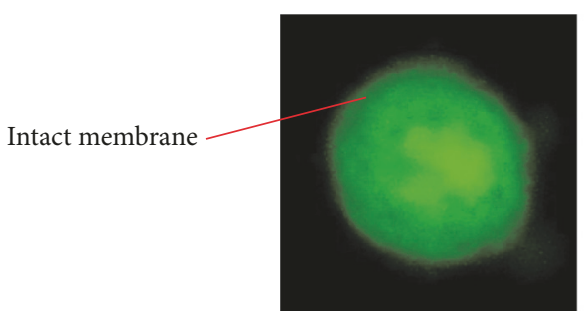

Viable

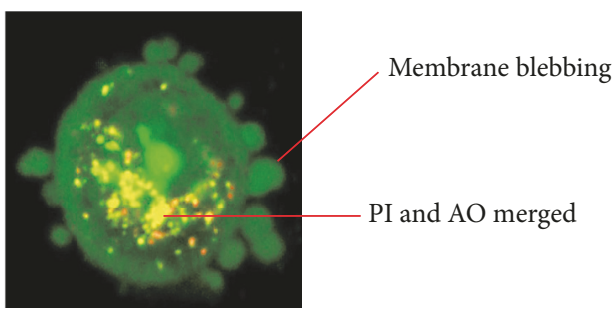

Apoptotic

(a)

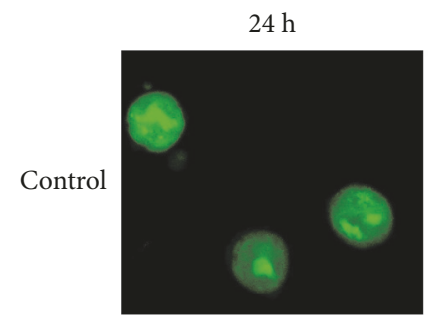

$48 \mathrm{~h}$
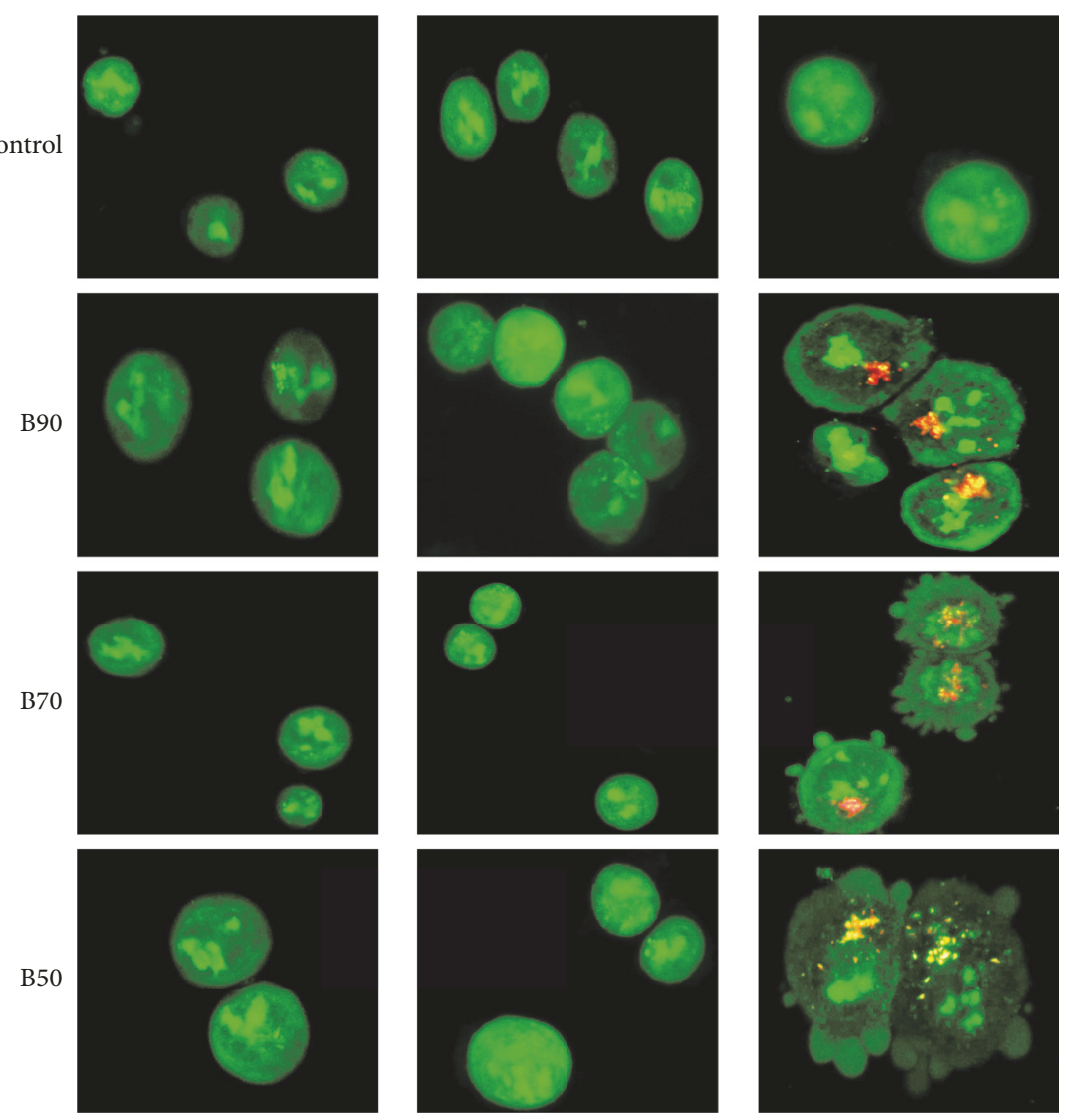

(b)

FIGURE 2: Morphological observation of B. frutescens leaves extracts treated MCF-7 cells using AO/PI dual staining at X400 magnifications. (a) Observation of morphological changes in MCF-7 cells. Viable cells are green stained cells with intact nucleus, condensed chromatin marked by intense green stained chromatin, membrane blebbing indicated by the outgrowth of plasma membrane and apoptotic cells are characterised by nuclear disintegration and leakage of plasma membrane. (b) MCF-7 cells were either treated without (untreated control) or with $B$. frutescens branches extracts (B90, B70, and B50) at their respective $\mathrm{IC}_{50}$ values and incubated for 24,48 , and $72 \mathrm{~h}(\mathrm{n}=3 \mathrm{independent}$ experiments, magnification X100).

summarized in Table 1(b). Alkaloid was not included due to its low level compared to other secondary metabolites measured. Similar ratio profile of quantitative estimation of secondary metabolite was observed among the $B$. frutescens extracts tested. B70 and WB exhibited the same ratio profile of triterpenoids, flavonoids, and phenols content (1: 8: 3) (Table $1(\mathrm{~b})$ ). The variation activity among cell death and glucose uptake inhibition strongly suggests the presence of different types of secondary metabolites in the extracts

\section{Conclusions}

The cytotoxic activity of $B$. frutescens extracts against MCF7 and MDA-MB-231 cells was determined at $72 \mathrm{~h}$. However, the $\mathrm{IC}_{50}$ value was only obtained in MCF-7 cells as compared to MDA-MB-231 cells. Hence, the cytotoxicity of B. frutescens branches extracts was more potent in MCF7 cells compared to MDA-MB-231 cells. The induction of cell death observed in MCF-7 cells was supported with 

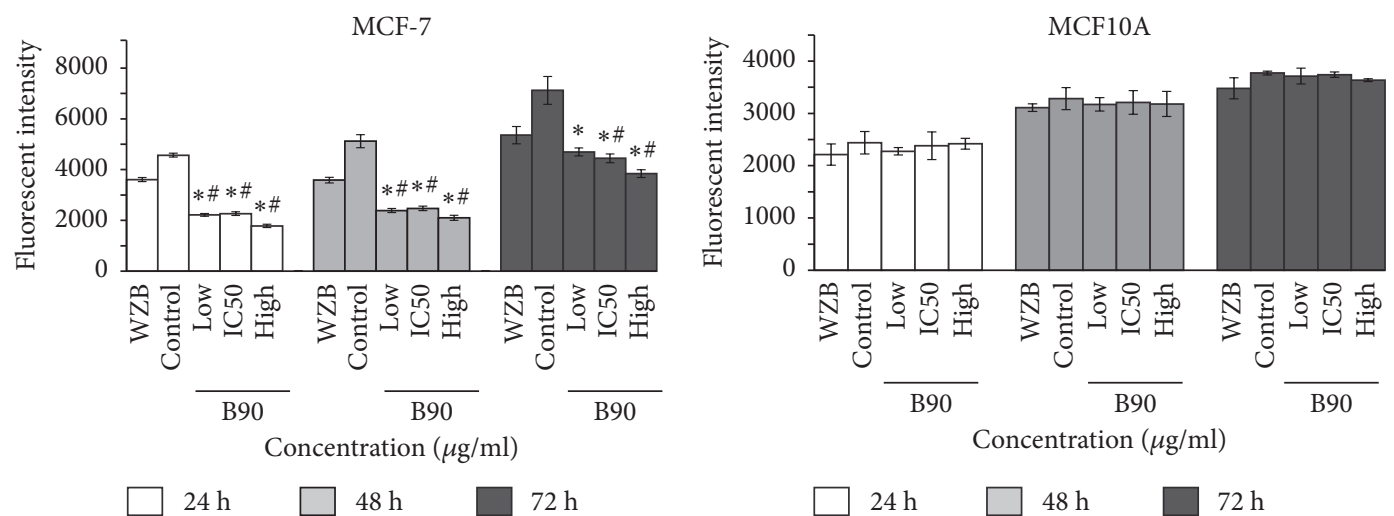

(a)
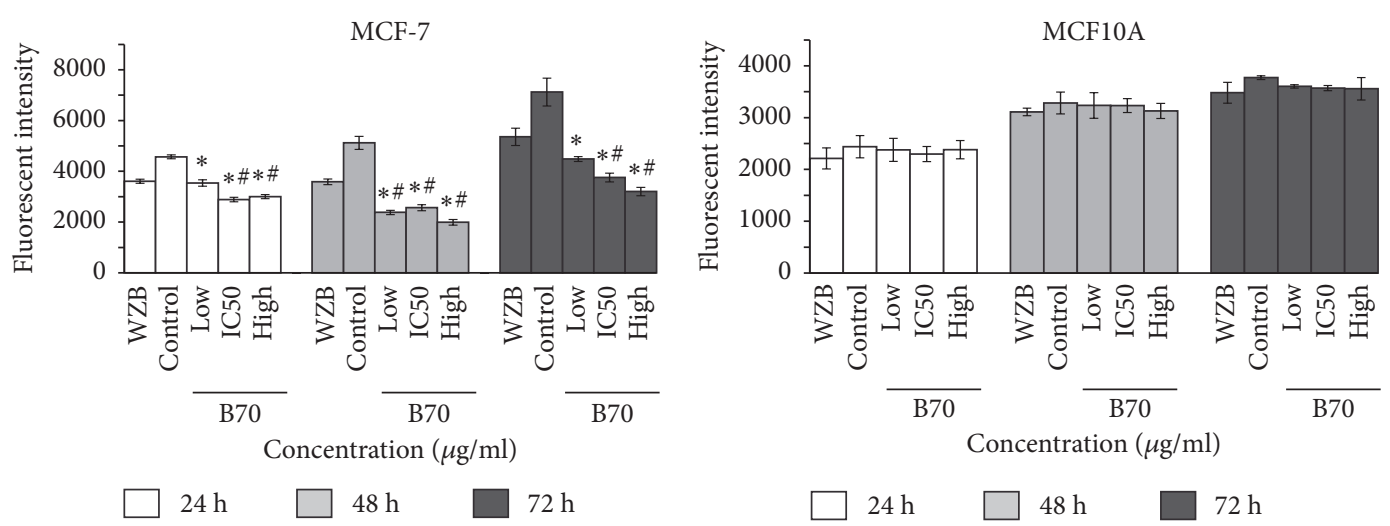

(b)
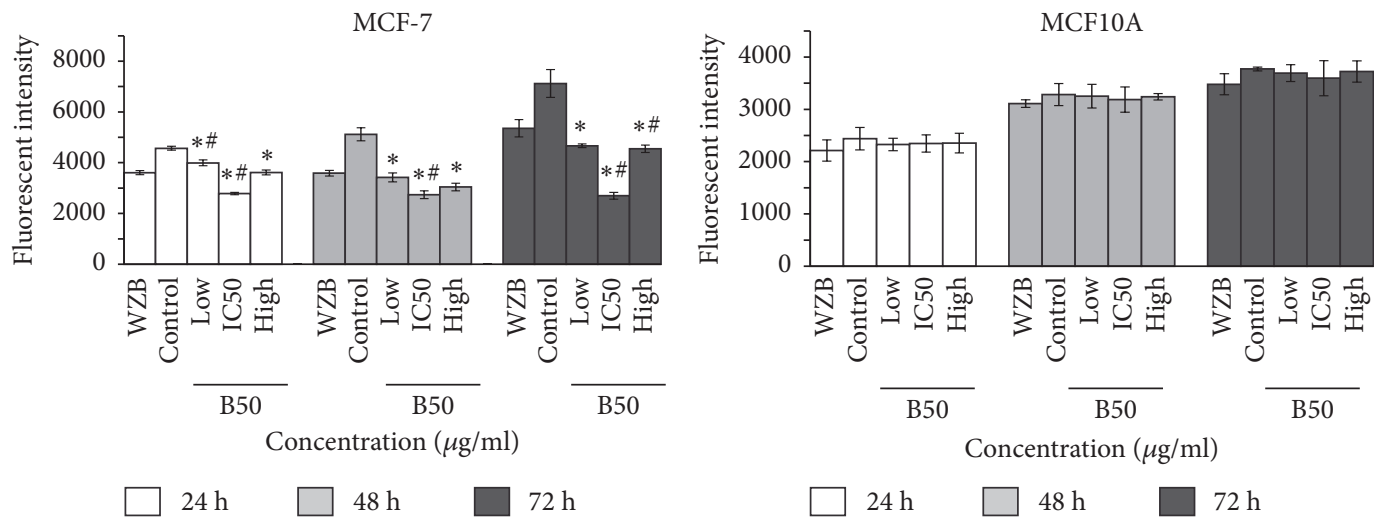

(c)

Figure 3: Inhibition of glucose uptake of B. frutescens leaves extracts after 24, 48, and $72 \mathrm{~h}$ of incubation. MCF-7 (left panels) or MCF10A

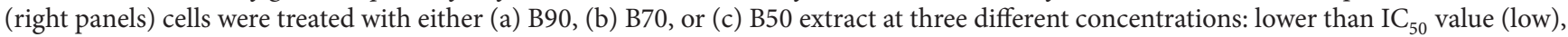
$\mathrm{IC}_{50}$ value (IC50), and higher than $\mathrm{IC}_{50}$ value (high) for 24,48 , and $72 \mathrm{~h}$. WZB117 served as positive control whilst DMSO is the vehicle control (control). Data is expressed as mean \pm standard error mean based on four independent experiments with triplicate wells for each concentration. $* \mathrm{p}<0.01$, compared with the untreated control (control); $\# \mathrm{p}<0.01$, compared with the positive control (WZB117).

the results obtained from AO/PI staining. Morphological changes showed evidence of early apoptosis in MCF-7 cells. All extracts selectively inhibited glucose uptake in breast cancer cells as early as $24 \mathrm{~h}$ after treatment. To our knowledge, this is the first study to report the role of $B$. frutescens branches extracts in modulating glucose in cancer cells. The preliminary secondary metabolites screening suggests that the branches extracts contain high flavonoids and undetectable level of alkaloids. However, the bioactive compound of $B$. frutescens branches extracts involved in eliminating breast cancer cells warrants further investigation. 


\section{Abbreviations}

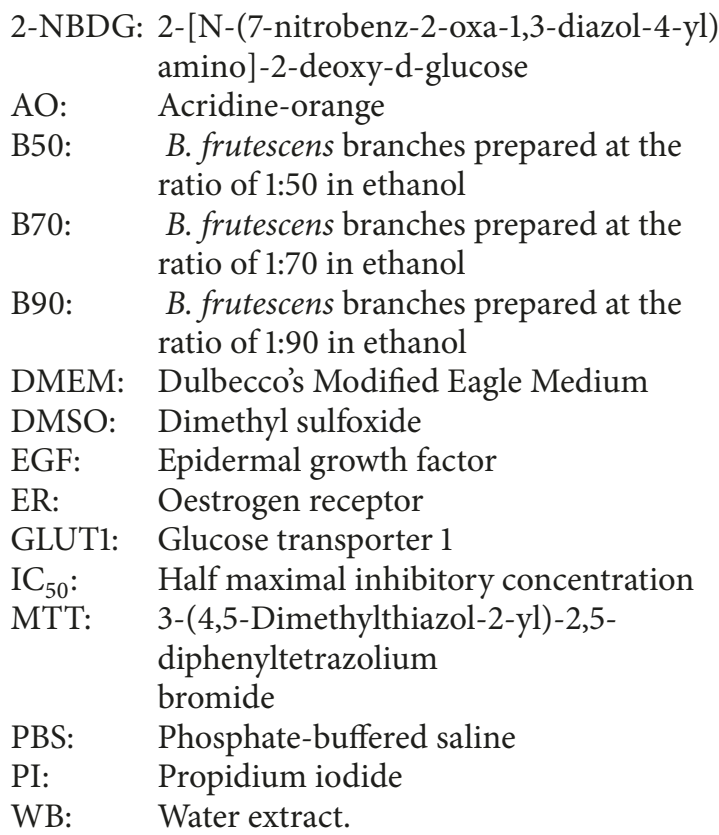

\section{Data Availability}

The data used to support the findings of this study are available from the corresponding author upon request.

\section{Conflicts of Interest}

We wish to confirm that there are no known conflicts of interest associated with this publication and there has been no significant financial support for this work that could have influenced its outcome.

\section{Acknowledgments}

We thank the Universiti Putra Malaysia (Programme Grant: Putra Grant GP-IPM/2014/9445100) for supporting and funding this work. Both M. F. Mustafa and S. H. Shahruzaman were supported by Graduate Research Fellowship from Universiti Putra Malaysia. S. H. Shahruzaman was also supported by MyBrain program from Malaysian Ministry of Higher Education.

\section{References}

[1] N. S. Ahmad, M. N. A. Ghani, A. Manaf Ali, S. A. Tajudin Tuan Johari, and M. H. Harun, "High performance liquid chromatography (HPLC) profiling analysis and bioactivity of baeckea frutescens L. (Myrtaceae)," Journal of Plant Studies, vol. 1, 2012.

[2] A. R. Bean, "A revision of Baeckea (Myrtaceae) in eastern Australia, Malesia and south-east Asia," Telopea, vol. 7, no. 3, pp. 245-268, 1997.

[3] A. M. Adib, F. Jamaludin, L. S. Kiong, N. Hashim, and Z. Abdullah, "Two-dimensional correlation infrared spectroscopy applied to analyzing and identifying the extracts of Baeckea frutescens medicinal materials," Journal of Pharmaceutical and Biomedical Analysis, vol. 96, pp. 104-110, 2014.

[4] J.-K. Hwang, J.-S. Shim, and J.-Y. Chung, "Anticariogenic activity of some tropical medicinal plants against Streptococcus mutans," Fitoterapia, vol. 75, no. 6, pp. 596-598, 2004.

[5] S. Razmavar, M. A. Abdulla, S. B. Ismail, and P. Hassandarvish, "Antibacterial activity of leaf extracts of Baeckea frutescens against methicillin-resistant Staphylococcus aureus," BioMed Research International, vol. 2014, Article ID 521287, 5 pages, 2014.

[6] T. T. Vu, H. Kim, V. K. Tran et al., "In vitro antibacterial activity of selected medicinal plants traditionally used in Vietnam against human pathogenic bacteria," BMC Complementary and Alternative Medicine, vol. 16, 32, 2016.

[7] S. Navanesan, N. A. Wahab, S. Manickam, and K. S. Sim, "Evaluation of selected biological capacities of Baeckea frutescens," BMC Complementary and Alternative Medicine, vol. 15, no. 186, 2015.

[8] B.-X. Jia, Y.-X. Zhou, X.-Q. Chen et al., "Structure determination of baeckeins C and D from the roots of Baeckea frutescens," Magnetic Resonance in Chemistry, vol. 49, no. 11, pp. 757-761, 2011.

[9] K. Kamiya and T. Satake, "Chemical constituents of Baeckea frutescens leaves inhibit copper-induced low-density lipoprotein oxidation," Fitoterapia, vol. 81, no. 3, pp. 185-189, 2010.

[10] Y. Fujimoto, S. Usui, M. Making, and M. Sumatra, "Phloroglucinols from Baeckea frutescens," Phytochemistry, vol. 41, no. 3, pp. 923-925, 1996.

[11] J. Hou, C. Guo, J. Zhao, Q. He, B. Zhang, and H. Wang, "Frutescone A-G, Tasmanone-Based Meroterpenoids from the aerial parts of Baeckea frutescens," The Journal of Organic Chemistry, vol. 82, no. 3, pp. 1448-1457, 2017.

[12] T. Ito, K. Nisa, S. K. Rakainsa, S. Lallo, and H. Morita, "New phloroglucinol derivatives from Indonesian Baeckea frutescens," Tetrahedron, vol. 73, no. 8, pp. 1177-1181, 2017.

[13] T. Ito, K. Nisa, T. Kodama et al., "Two new cyclopentenones and a new furanone from Baeckea frutescens and their cytotoxicities," Fitoterapia, vol. 112, pp. 132-135, 2016.

[14] I. Jantan, A. S. Ahmad, S. A. A. Bakar et al., "Constituents of the essential oil of baeckea frutescens 1 . from malaysia," Flavour and Fragrance Journal, vol. 13, pp. 245-247, 1998.

[15] B.-X. Jia, X.-L. Zeng, F.-X. Ren et al., "Baeckeins F-I, four novel C-methylated biflavonoids from the roots of Baeckea frutescens and their anti-inflammatory activities," Food Chemistry, vol. 155, pp. 31-37, 2014.

[16] B.-X. Jia, A. Jia, C.-J. Li et al., "Baeckeins J and K, two novel c-methylated biflavonoids from the roots of baeckea frutescens and their cytoprotective activities," Helvetica Chimica Acta, vol. 99, no. 7, pp. 499-505, 2016.

[17] B.-X. Jia, F.-X. Ren, L. Jia, X.-Q. Chen, J. Yang, and Q. Wang, "Baeckein E, a new bioactive C-methylated biflavonoid from the roots of Baeckea frutescens," Natural Product Research (Formerly Natural Product Letters), vol. 27, no. 22, pp. 20692075, 2013.

[18] B.-X. Jia, J. Yang, X.-Q. Chen, Y. Cao, M.-X. Lai, and Q. Wang, "Baeckeins A and B, two novel 6-methylflavonoids from the roots of Baeckea frutescens," Helvetica Chimica Acta, vol. 94, no. 12, pp. 2283-2288, 2011.

[19] W.-J. Lu, Q.-K. Ya, J.-Y. Chen, and B.-M. Liu, "A new flavonol glycoside from Baeckea Frutescens L., Yaoxue Xuebao, vol. 43, no. 10, pp. 1032-1035, 2008. 
[20] M. Makino and Y. Fujimoto, "Flavanones from Baeckea frutescens," Phytochemistry, vol. 50, no. 2, pp. 273-277, 1999.

[21] K. Nisa, T. Ito, T. Kodama et al., "New cytotoxic phloroglucinols, baeckenones D-F, from the leaves of Indonesian Baeckea frutescens," Fitoterapia, vol. 109, pp. 236-240, 2016.

[22] K. Nisa, T. Ito, Subehan, T. Matsui, T. Kodama, and H. Morita, "New acylphloroglucinol derivatives from the leaves of Baeckea frutescens," Phytochemistry Letters, vol. 15, pp. 42-45, 2016.

[23] T. Satake, K. Kamiya, Y. Saiki et al., "Chromone C-glycosides from Baeckea frutescens," Phytochemistry, vol. 50, no. 2, pp. 303-306, 1999.

[24] N. T. Tam, D. T. Thuam, A. Bighelli et al., "Baeckea frutescens leaf oil from Vietnam: Composition and chemical variability," Flavour and Fragrance Journal, vol. 19, no. 3, pp. 217-220, 2004.

[25] W. Tsui and G. D. Brown, "Sesquiterpenes from Baeckea frutescens," Journal of Natural Products, vol. 59, no. 11, pp. 1084-1086, 1996.

[26] W.-Y. Tsui and G. D. Brown, "Chromones and chromanones from Baeckea frutescens," Phytochemistry, vol. 43, no. 4, pp. 871876, 1996.

[27] W.-Y. Tsui and G. D. Brown, "Unusual metabolites of Baeckea frutescens," Tetrahedron, vol. 52, no. 29, pp. 9735-9742, 1996.

[28] Q.-W. Yu, H. Wang, J.-T. Huo et al., "Suppression of Baeckea frutescens L. and its components on MyD88-dependent NF$\kappa \mathrm{B}$ pathway in MALP-2-stimulated RAW264.7 cells," Journal of Ethnopharmacology, vol. 207, pp. 92-99, 2017.

[29] T. Mosmann, "Rapid colorimetric assay for cellular growth and survival: application to proliferation and cytotoxicity assays," Journal of Immunological Methods, vol. 65, no. 1-2, pp. 55-63, 1983.

[30] M. Hassanein, B. Weidow, E. Koehler et al., "Development of high-throughput quantitative assays for glucose uptake in cancer cell lines," Molecular Imaging and Biology, vol. 13, no. 5, pp. 840-852, 2011.

[31] E. E. Abdul Hisam, M. S. Rofiee, A. M. Khalid et al., "Combined extract of moringa oleifera and Centella asiatica modulates oxidative stress and senescence in hydrogen peroxide-induced human dermal fibroblasts," Turkish Journal of Biology, vol. 42, no. 1, pp. 33-44, 2018.

[32] Z. Darzynkiewicz, "Chapter 27 differential staining of DNA and RNA in intact cells and isolated cell nuclei with acridine orange," Methods in Cell Biology, vol. 33, pp. 285-298, 1990.

[33] A. Ishaque and M. Al-Rubeai, "Measurement of apoptosis in cell culture," Methods, vol. 24, pp. 285-299, 2007.

[34] X. Hu, M. Chao, and H. Wu, "Central role of lactate and proton in cancer cell resistance to glucose deprivation and its clinical translation," Signal Transduction and Targeted Therapy, vol. 2, 2017. 


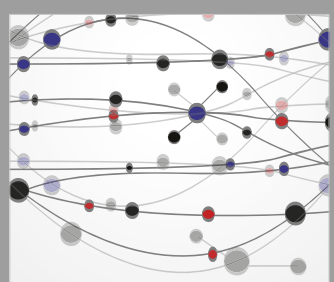

The Scientific World Journal
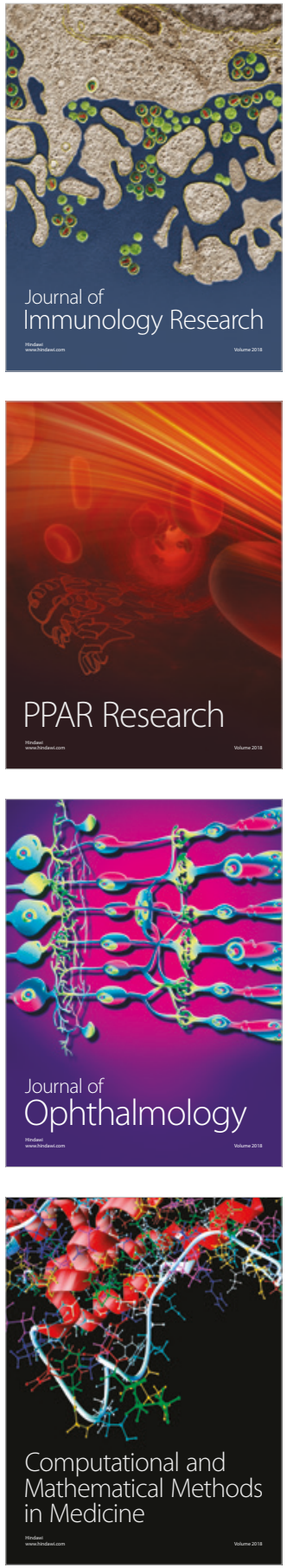

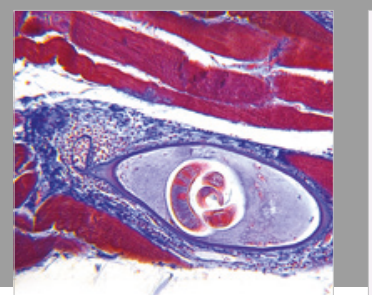

Gastroenterology Research and Practice

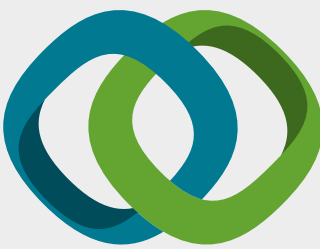

\section{Hindawi}

Submit your manuscripts at

www.hindawi.com
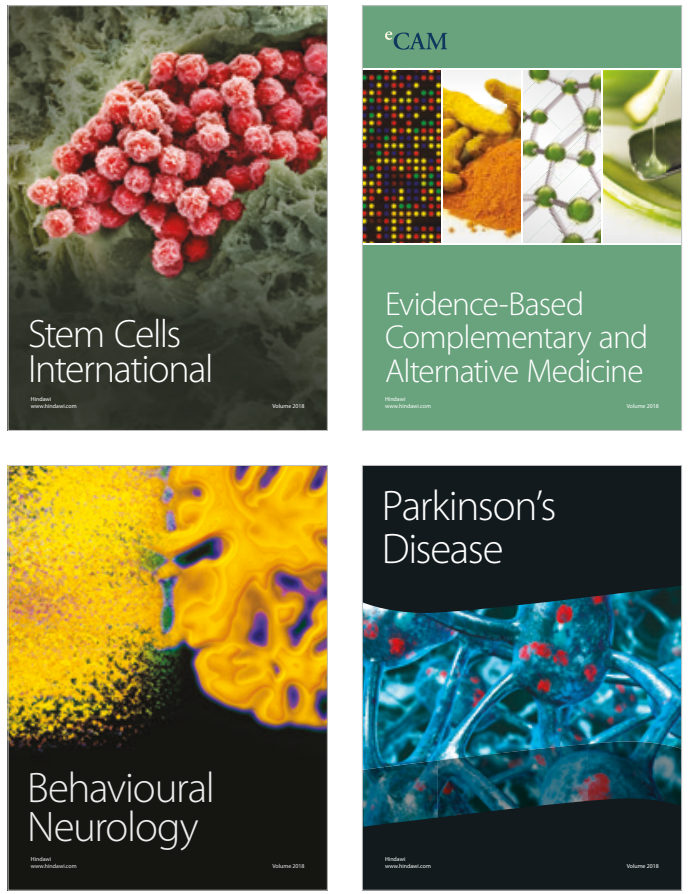

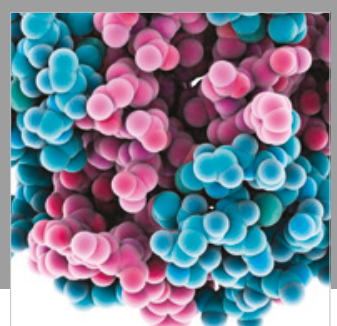

ournal of

Diabetes Research

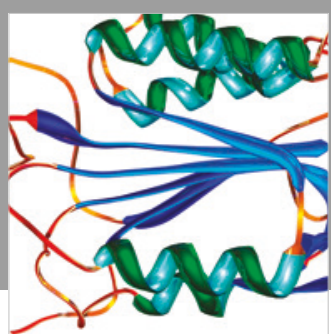

Disease Markers
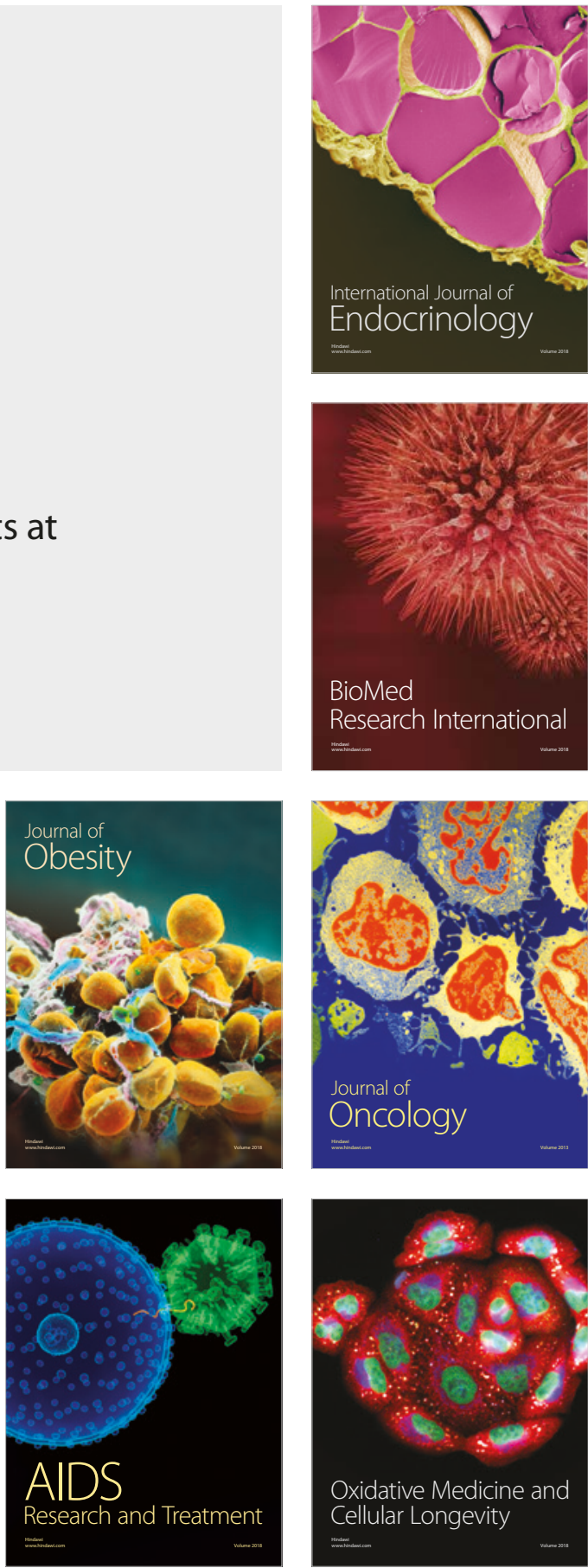